\title{
Anterior Cortical Window Technique Instead of Extended Trochanteric Osteotomy in Revision Total Hip Arthroplasty: A Minimum 10-Year Follow-up
}

\author{
Chan Ho Park, MD, Jiung Yeom, MD*, Jung-Wee Park, MD*, Seok Hyung Won, MD*, \\ Young-Kyun Lee, $\mathrm{MD}^{*}$, Kyung-Hoi Koo, $\mathrm{MD}^{*,+}$ \\ Department of Orthopaedic Surgery, Yeungnam University Medical Center, Daegu, \\ ${ }^{*}$ Department of Orthopedic Surgery, Seoul National University Bundang Hospital, Seongnam, \\ ${ }^{\dagger}$ Department of Orthopedic Surgery, Seoul National University College of Medicine, Seoul, Korea
}

Background: The anterior cortical window technique was developed to facilitate stem removal in revision total hip arthroplasty (THA). In this technique, only the anterior cortex of the proximal femur is osteomized; the trochanter, lateral cortex, and medial cortex remain intact. Therefore, a new stem can be press-fitted into the femur and mediolateral stability can be obtained. However, the long-term results of revision THA using this technique are unknown. We report the outcome and survivorship at a minimum of 10-year follow-up.

Methods: From May 2003 to April 2006, 69 patients (75 hips) underwent revision THA using an anterior cortical window and a cementless distal interlocking stem. Of these, 50 patients (56 hips) were followed up for 10 to 13 years (mean, 11.5 years). There were 26 men (29 hips) and 24 women (27 hips) with a mean age of 51.2 years (range, 29 to 82 years) at the time of revision arthroplasty. We evaluated radiographs, Harris hip score, University of California at Los Angeles (UCLA) activity score, Koval category, and survivorship.

Results: Nonunion of the osteotomy occurred in one hip (2\%). Five stems $(8.9 \%)$ subsided $5 \mathrm{~mm}$ or more. At the final evaluation, the mean Harris hip score, UCLA activity score, and the Koval category were 82.5, 4.6, and 1.5, respectively. Survivorship with any operations as the end point was $80.4 \%$ and that with stem-revision as the end point was $91.1 \%$.

Conclusions: With use of an anterior cortical window, a well-fixed stem can be easily removed, and a new stem can be inserted with firm mediolateral stability in the proximal femur in revision THA. We recommend using this technique instead of the extended trochanteric osteotomy in revision THA.

Keywords: Arthroplasty, Replacement, Hip, Reoperation, Survival rate

Received April 2, 2019; Accepted May 27, 2019

Chan Ho Park and Jiung Yeom contributed equally to this work as first authors.

Correspondence to: Young-Kyun Lee, MD

Department of Orthopedic Surgery, Seoul National University Bundang

Hospital, 82 Gumi-ro 173beon-gil, Bundang-gu, Seongnam 13620, Korea

Tel: +82-31-787-7204, Fax: +82-31-787-4095

E-mail: ykleemd@gmail.com
The number of revision hip arthroplasties has been increasing over the past 20 years ${ }^{1,2)}$ with the increase in the incidence of primary total hip arthroplasty (THA). ${ }^{3)}$ In some revisions, well-fixed femoral stems should be removed because of the incompatibility with bearing materials, periprosthetic joint infection, or damage of trunnion. The removal of a well-fixed stem is challenging, and thus several surgical techniques have been developed. Since introduced by Younger et al.,") the extended trochanteric 
Park et al. Anterior Cortical Window in Revision Hip Arthroplasty

Clinics in Orthopedic Surgery • Vol. 11, No. 4, $2019 \bullet$ www.ecios.org

osteotomy (ETO) has been widely used to facilitate exposure and removal of the stem. ${ }^{5)}$ However, this technique has been associated with several complications including intraoperative femoral fracture, ${ }^{6}$ weakness of the abductor mechanism, trochanteric fracture, and postoperative stem loosening. ${ }^{7-9)}$

In 2003, the anterior cortical window technique was introduced as a method that provides solutions to such problems. ${ }^{10)}$ This technique allows for easy removal of a well-fixed femoral stem or cement mantle and stable fixation of a new stem. Moreover, the osteotomy can be easily fixed with several cerclage wires. ${ }^{11-14)}$ Therefore, we hypothesized that the anterior cortical window technique would be an effective method that causes less damage to the host bone in revision surgery. In this study, we investigated intraoperative and postoperative complications, radiological and clinical results (such as patient-reported outcome and abductor deficiency), and survivorship of revision THA performed using an anterior cortical window at a minimum follow-up of 10 years.

\section{METHODS}

\section{Patient Selection and Demographics}

Sixty-nine consecutive patients (75 hips) underwent revision THA with use of the anterior cortical window technique at our institution from May 2003 to April 2006. Among the 69 patients, 14 patients (14 hips) were lost to follow-up, and five patients (five hips) died of causes unrelated to revision surgery before the minimum follow-up of 10 years. The remaining 50 patients ( 56 hips), who were followed up for 10 to 13 years (mean, 11.5 years), were included in this study (Fig. 1).

There were 26 men (29 hips) and 24 women (27 hips), and their mean age at the time of revision THA was 51.2 years (range, 29 to 82 years). Their mean body mass

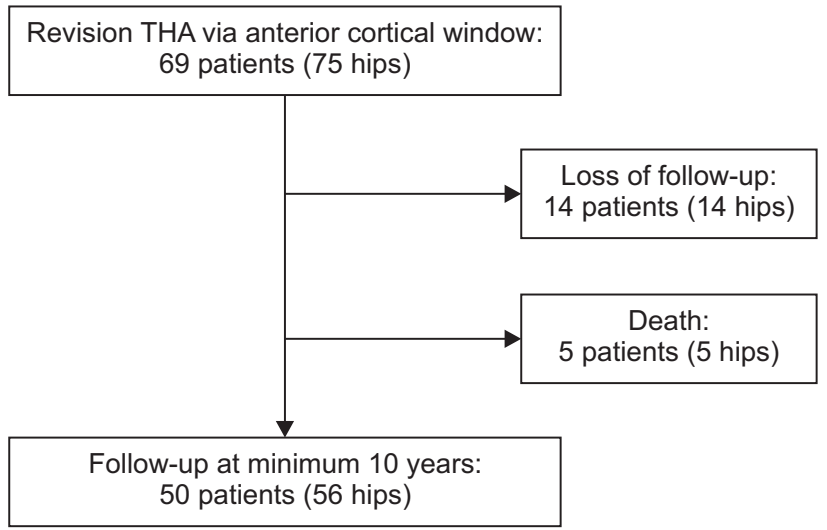

Fig. 1. Flowchart of the study. THA: total hip arthroplasty. index was $23.3 \mathrm{~kg} / \mathrm{m}^{2}$ (range, 15.7 to $32.1 \mathrm{~kg} / \mathrm{m}^{2}$ ). Forty-six patients (52 hips) had cementless stems, and four patients (four hips) had cemented stems. Mean interval between previous hip arthroplasty and the revision THA was 10.8 years (range, 6.8 to 18.7 years). Reasons for revision surgery were cup loosening in 34 hips, loosening of cup and stem in 18 hips, stem loosening in two hips, liner wear in one hip, and recurrent dislocation after THA in one hip. Although the most common reason for revision was cup loosening, previous stems and femoral heads had to be revised as well as the acetabular cup and liner because scratches of the metallic femoral head were found during revision and new femoral heads were not compatible with previous stems (Table 1).

\section{Surgical Technique}

All operations were performed by two senior surgeons

Table 1. Patient Demographics

\begin{tabular}{|c|c|}
\hline Variable & Value \\
\hline Sex (male:female) & 26 (29 Hips):24 (27 Hips) \\
\hline Age (yr) & $51.2(29-82)$ \\
\hline Body mass index $\left(\mathrm{kg} / \mathrm{m}^{2}\right)$ & $23.3(15.7-32.1)$ \\
\hline \multicolumn{2}{|l|}{ Reason for revision } \\
\hline Cup loosening & $34(60.7)$ \\
\hline Total loosening & $18(32.1)$ \\
\hline Stem loosening & $2(3.6)$ \\
\hline Liner wear & $1(1.8)$ \\
\hline Recurrent dislocation & $1(1.8)$ \\
\hline \multicolumn{2}{|l|}{ Fixation type of previous stem } \\
\hline Cementless & $52(92.9)$ \\
\hline Cemented & $4(7.1)$ \\
\hline \multicolumn{2}{|l|}{ Previous stem } \\
\hline Omnifit & $26(46.4)$ \\
\hline S-ROM & $7(12.5)$ \\
\hline Anatomique Benoist Gerar & $6(10.7)$ \\
\hline Euroform & $5(8.9)$ \\
\hline CLS & $3(5.4)$ \\
\hline AML & $3(5.4)$ \\
\hline Others & $6(10.7)$ \\
\hline
\end{tabular}

Values are presented as mean (range) or number (\%). AML: anatomic medullary locking. 
Park et al. Anterior Cortical Window in Revision Hip Arthroplasty

Clinics in Orthopedic Surgery • Vol. 11, No. 4, $2019 \bullet$ www.ecios.org

(KHK, YMK) via the direct lateral approach by using the anterior cortical window technique described by Kim et al. ${ }^{10)}$ After deciding the range of window by the length of cement mantle or the porous coating on the previous stem, the surgeons made a longitudinal window with a thin osteotome and a sagittal saw. Then, the stem or cement mantle was removed with a thin osteotome and a curved sagittal saw (Fig. 2).

In all revisions, cementless prostheses (Plasmacup cup and Bicontact long stem; Aesculap, Tuttlingen, Germany) and alumina ceramic-on-ceramic bearing (Biolox forte; CeramTec, Plochingen, Germany) were used (Fig. 3). The stem had a distal interlocking screw. After insertion of a new stem, the widow fragment was fixed with cerclage wires (Smith \& Nephew, London, UK). The diameter of femoral head was $28 \mathrm{~mm}$ in 53 hips and $32 \mathrm{~mm}$ in three hips. Patients were encouraged to walk with two crutches and toe-touch weight bearing for 2 months, and then weight-bearing was allowed as tolerated.

\section{Follow-up Evaluations}

Routine follow-up visits were scheduled at 6 weeks, 3, 6, and 12 months, and yearly thereafter. Patients who did not return for regularly scheduled visits were contacted by telephone. Clinical outcome was assessed by the modified Harris hip score, University of California at Los Angeles (UCLA) activity score, and Koval ambulation category at each visit. ${ }^{15)}$ The abductor muscle strength was evaluated by the Medical Research Council scale. ${ }^{16)}$ Cerclage wiringrelated complications including wire breakage, wire bursitis, and trochanteric pain were recorded.

The radiographic evaluations were done by two independent observers (CHP, JY) who did not participate in the index revision. The 6-week postoperative radiographs were considered as the baseline radiographs for all comparisons. Subsidence of the femoral stem, union of the osteotomized fragment, and periprosthetic bone loss were assessed. Subsidence of the stem was defined as the change of $5 \mathrm{~mm}$ or more in the distance between the superolateral edge at the shoulder of the prosthesis and the tip of the greater trochanter on the anteroposterior radiograph. ${ }^{17,18)}$ Periprosthetic bone loss was evaluated according to the criteria by Capello et al., ${ }^{19)}$ and the location was recorded according to the seven zones described by Gruen et al. ${ }^{20)}$

Descriptive statistics were used to summarize patient demographics. Survival analysis was performed with the Kaplan-Meier method, and the 95\% confidence interval (CI) was calculated. Statistical analysis was performed using IBM SPSS ver. 20.0 (IBM Corp., Armonk, NY, USA). We conducted this study in compliance with the principles of the Declaration of Helsinki. The protocol of this study was reviewed and approved by the Institutional Review Board of Seoul National University Hospital (IRB No. B-1512-328-103). Informed consent was waived.

\section{RESULTS}

The median operation time was 350 minutes (range, 175 to 650 minutes), and the median blood loss was $1,250 \mathrm{~mL}$ (range, 500 to $4,000 \mathrm{~mL}$ ). There was no statistically significant difference in the operation time and blood loss according to the stems used in primary THA ( $p=0.67$ and $p$ $=0.461$, respectively). Intraoperative femoral fractures occurred in two hips (2.6\%) during creation of the anterior

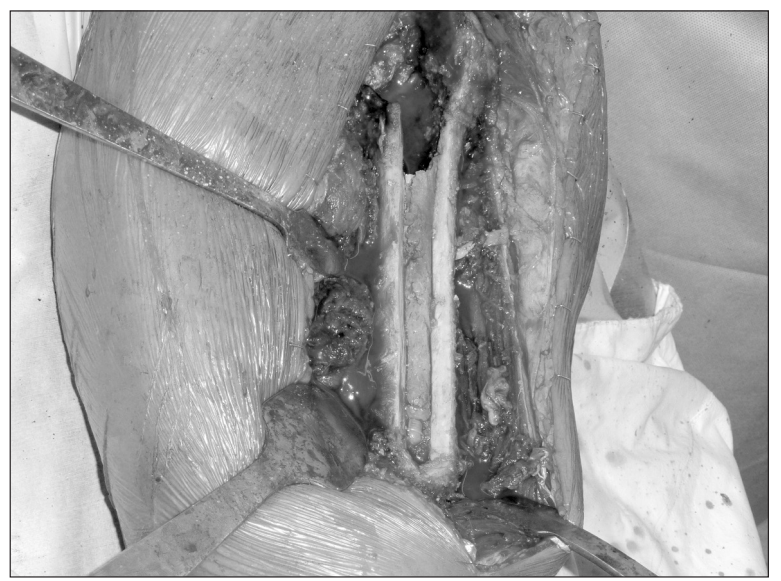

Fig. 2. Intraoperative photo of the anterior cortical window to remove a cemented stem.

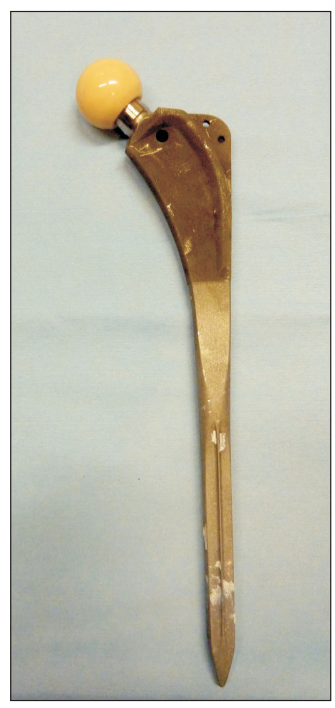

Fig. 3. Bicontact long stem with a distal interlocking screw. 
Park et al. Anterior Cortical Window in Revision Hip Arthroplasty

Clinics in Orthopedic Surgery • Vol. 11, No. 4, 2019• www.ecios.org

cortical window. The fractures occurred at the distal end of the anterior cortical window and in the cases where the anatomic medullary locking (AML; Depuy Synthes, Warsaw, IN, USA) stem was used previously. One fracture was successfully fixed with a plate during the index revision. The fracture healed and the stem was stable without subsidence at 11 years after the revision. The other fracture was fixed with cerclage bands during the index revision. However, nonunion occurred postoepratively and the stem progressively subsided. Thus, the stem was re-revised, and the nonunion was treated by plate fixation and autogenous bone graft.

Five hips dislocated after the revision. Four dislocations were successfully treated with manual reduction and a hip brace used for 2 months. The remaining one dislocation was caused by cup malposition and treated with re-

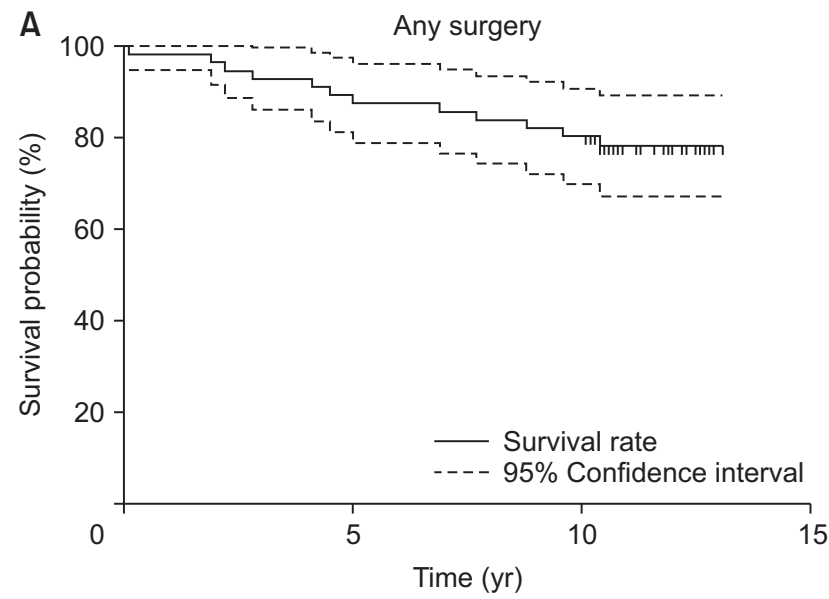

peated revision of the cup. Sciatic nerve palsy occurred in one hip, which was restored at 1 year after the revision.

Subsidence of the stem was observed in five hips $(8.4 \%)$ during 1 year after the revision. There was no statistically significant difference in the incidence of subsidence according to the stems used in primary THA ( $p=$ 0.878 ). Subsidence was not progressive in three hips; it was progressive in the remaining two hips, which necessitated a repeated revision of the stem. One of these hips also had intraoperative femoral fracture and nonunion. Cortical porosis around the stem was seen in 14 hips (25\%): in Gruen zones 1 and 7 in nine hips and in Gruen zone 1 in five hips. Breakage of the cerclage band was observed in 16 hips. Two of them were associated with symptomatic bursitis and underwent removal of the cerclage band.

There were two periprosthetic joint infections. One

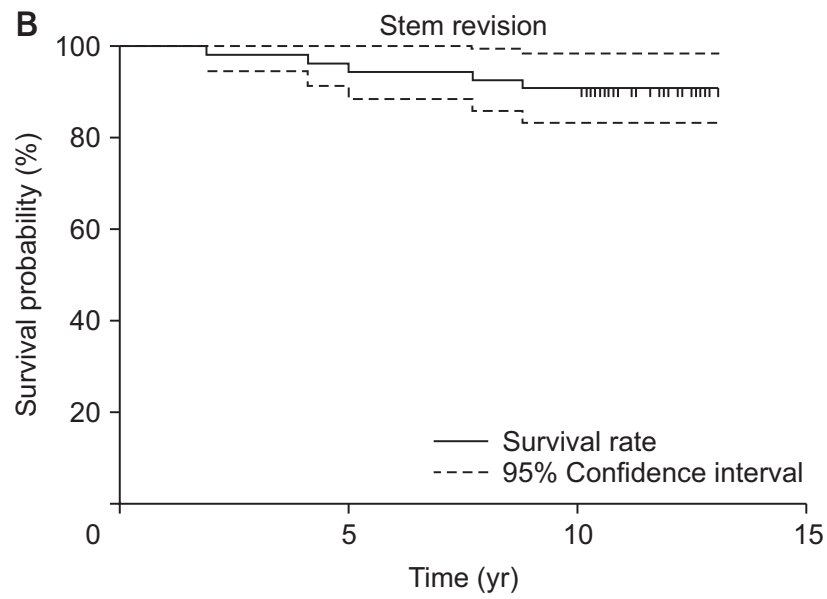

Fig. 4. Kaplan-Meier survival curve with any surgery $(A)$ and re-revision of femoral stem $(B)$ as the end point.
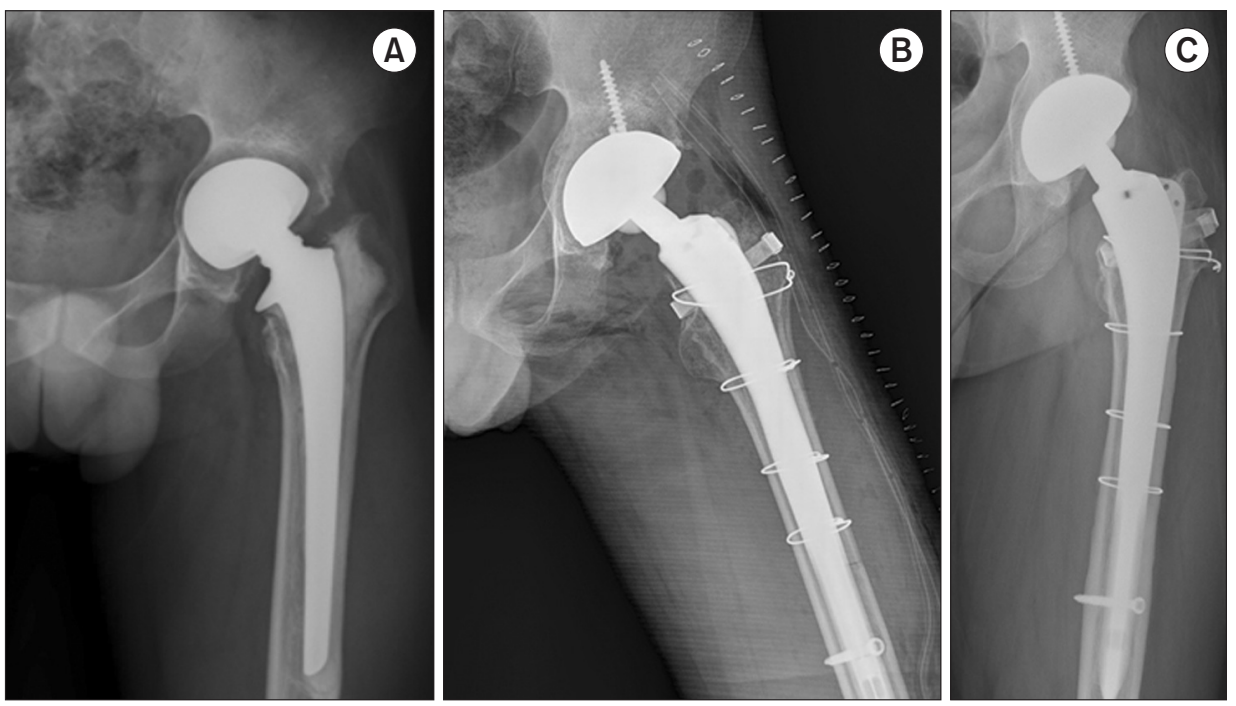

Fig. 5. (A) A 28-year-old man had acetabular protrusion after bipolar hemiarthroplasty. (B) Total revision was performed by using an anterior cortical window. (C) The stem was maintained without subsidence at 11.3 years after revision arthroplasty. 
Park et al. Anterior Cortical Window in Revision Hip Arthroplasty

Clinics in Orthopedic Surgery • Vol. 11, No. 4, $2019 \bullet$ www.ecios.org

Table 2. Comparison of the Present Study with Previous Studies Using Extended Trochanteric Osteotomy

\begin{tabular}{|c|c|c|c|c|c|c|c|}
\hline Study & $\begin{array}{l}\text { No. of } \\
\text { hips }\end{array}$ & $\begin{array}{l}\text { Follow-up } \\
\text { period (mo) }\end{array}$ & $\begin{array}{c}\text { Type of } \\
\text { revision stem }\end{array}$ & Dislocation & Nonunion & $\begin{array}{c}\text { Stem } \\
\text { loosening }\end{array}$ & Complication \\
\hline Chen et al. $(2000)^{5)}$ & 45 & 45 & $\begin{array}{l}\text { Extensively } \\
\text { porous-coated }\end{array}$ & $5(11)$ & $1(2.2)$ & NA & $\begin{array}{l}1 \text { Superficial infection } \\
1 \text { Deep infection } \\
1 \text { Sciatic nerve palsy } \\
2 \text { Fracture of osteotomy fragment }\end{array}$ \\
\hline Miner et al. $(2001)^{21)}$ & 166 & 48 & $\begin{array}{l}\text { Extensively } \\
\text { porous-coated }\end{array}$ & $17(10.2)$ & $2(1.2)$ & $1(0.6)$ & $\begin{array}{l}3 \text { Superficial infection } \\
1 \text { Deep infection } \\
3 \text { Sciatic nerve palsy } \\
18 \text { Intraoperative femoral fracture }\end{array}$ \\
\hline Huffman and Ries $(2003)^{7 /}$ & 43 & 16.6 & $\begin{array}{l}\text { Extensively } \\
\text { porous-coated }\end{array}$ & $3(7.0)$ & 0 & 0 & $\begin{array}{l}1 \text { Deep infection } \\
5 \text { Intraoperative femoral fracture }\end{array}$ \\
\hline MacDonald et al. $(2003)^{9, * *}$ & 45 & 44.6 & $\begin{array}{l}\text { Extensively } \\
\text { porous-coated }\end{array}$ & NA & $5(11.1)$ & $1(2.2)$ & $\begin{array}{l}2 \text { Fragment escape } \\
2 \text { Fracture of osteotomy fragment }\end{array}$ \\
\hline Mardones et al. $(2005)^{6)}$ & 75 & 24 & $\begin{array}{l}\text { Extensively } \\
\text { porous-coated }\end{array}$ & NA & $1(4.2)$ & $1(4.2)$ & $\begin{array}{l}3 \text { Fracture of osteotomy fragment } \\
9 \text { Intraoperative femoral fracture }\end{array}$ \\
\hline Charity et al. $(2013)^{8)}$ & 18 & 123 & Cemented & NA & 0 & 0 & 2 Fracture of osteotomy fragment \\
\hline This study $(2018)^{*}$ & 56 & 138.5 & $\begin{array}{l}\text { Proximal porous- } \\
\text { coated with } \\
\text { distal locking } \\
\text { screw }\end{array}$ & $5(8.9)$ & $1(1.8)$ & $2(3.6)$ & $\begin{array}{l}1 \text { Deep infection } \\
1 \text { Sciatic nerve palsy } \\
2 \text { Intraoperative femoral fracture }\end{array}$ \\
\hline
\end{tabular}

Values are presented as mean or number (\%).

NA: not available.

*Via the direct lateral approach.

was a superficial infection, which was detected at postoperative 4 weeks. It was treated by incision and drainage, and there was no recurrence. The other infection occurred at postoperative 8 years and was treated by two-stage revision. One Vancouver type B1 periprosthetic femoral fracture occurred 2 years postoperatively and was successfully treated with open reduction and internal fixation using dual plates.

At the final follow-up, the mean Harris hip score was 82.5 (range, 31.9 to 100 ) and the mean UCLA activity score was 4.6 (range, 1 to 8 ). The mean abductor muscle strengh was 4.1 (range, 3 to 5) and the mean Koval category was 1.5 (range 1 to 7 ).

Twelve patients (12 hips, 21.4\%) underwent repeated operation because of stem loosening (two hips), cerclage wire/band-related bursitis (two hips), cup loosening (four hips), periprosthetic femoral fracture (one hip), periprosthetic joint infection (one hip), removal of distal locking screw due to soft tissue irritation (one hip), or irrigation and debridement for superficial infection (one hip). Kaplan-Meier survivorship with any surgery as the end point was $80.4 \%$ (95\% CI, $68.5 \%$ to $88.2 \%$ ), and that with stem revision as the end point was $91.1 \%$ (95\% CI, $83.6 \%$ to $98.6 \%$ ) at 10 years after the index revision (Figs. 4 and 5).

\section{DISCUSSION}

This study showed a satisfactory long-term results and survivorship of revision THA using an anterior cortical window in a relatively large number of patients. In our patients, we used ceramic-on-ceramic bearing, which might have positively affected the survivorship. ${ }^{22}$ Removal of well-fixed cementless stem and cement mantle is challenging and ETO has been widely used for the removal. Charity et al. ${ }^{8)}$ reported excellent results of ETO using a cemented stem at a mean follow-up of 123 months. However, the number of ETO cases was only 18. Otherwise, to the best of our knowledge, long-term results and survival rate of revision THA using ETO have not been reported yet.

Nonunion is the most common concern after trochanteric osteotomy. Reportedly, the nonunion rate of standard trochanteric osteotomy (STO) ranged from 5\% to $14 \%{ }^{23,24)}$ The nonunion rate has been decreased to $1 \%$ to $3 \%$ since the ETO was introduced. ${ }^{25)}$ In our patients, nonunion occurred in one femur $(1.8 \%)$ that had an intraoperative fracture. In our study of the anterior cortical window technique, the nonunion rate was lower than or comparable to that previously reported in STO and ETO 
Park et al. Anterior Cortical Window in Revision Hip Arthroplasty

Clinics in Orthopedic Surgery • Vol. 11, No. 4, $2019 \bullet$ www.ecios.org

studies (Table 2)..$^{5-9,21)}$

Because the osteotomized fragment in ETO is bigger than that in the anterior cortical window technique and the abductor muscle is attached onto the trochanteric fragment, ETO requires strong fixation of the greater trochanter. Various techniques and materials were introduced for the fixation ETO. ${ }^{726,27)}$ Although the fixation using a cable grip was excellent in a biomechanical study, cable griprelated complications appeared to be an issue. ${ }^{28)}$ However, the osteotomy fragment of the anterior cortical window is small, does not damage the abductor mechanism, can be fixed firmly by cerclage wires or bands, and does not require cable grip (Fig. 5).

In ETO, it is not feasible to press-fit the new stem in the proximal femur, and it is necessary to use a distally fitting stem. Distally fitting modular stems with an extensive porous coating were recommended for ETO ${ }^{25)}$ However, modular stems are associated with fracture at the modular junction. ${ }^{29)}$ In our study, all patients were operated with monolithic stems.

During osteotomy, the femur is vulnerable to intraoperative fractures. In our study, the incidence of intraoperative femoral fractures was 3.6\% (2/56), whereas the incidence ranged from $4 \%$ to $30 \%$ in previous studies of ETO. ${ }^{25,30)}$ When making an anterior cortical window, the surgeon should take care not to cause intraoperative fractures especially at the distal end of the anterior cortical window and to avoid extensive removal of the porouscoated stem, such as the AML stem.

One of the limitations of our study was the retrospective design without a control group. Thus, we compared the results of the anterior cortical window technique with those of ETO. Another limitation was that all the operations were performed by two high-volume surgeons; the results might have been different if the operations were performed by other surgeons. Despite these limitations, this is the first study to report the long-term result of revision THA using an anterior cortical window, which provided satisfactory results and survivorship in the long term. We recommend using this technique instead of ETO for revision THA.

\section{CONFLICT OF INTEREST}

No potential conflict of interest relevant to this article was reported.

\section{ACKNOWLEDGEMENTS}

We appreciate Young-Min Kim's (MD) contribution to this study.

\section{REFERENCES}

1. Kurtz S, Mowat F, Ong K, Chan N, Lau E, Halpern M. Prevalence of primary and revision total hip and knee arthroplasty in the United States from 1990 through 2002. J Bone Joint Surg Am. 2005;87(7):1487-97.

2. Yoon PW, Lee YK, Ahn J, et al. Epidemiology of hip replacements in Korea from 2007 to 2011. J Korean Med Sci. 2014;29(6):852-8.

3. Patel A, Pavlou G, Mujica-Mota RE, Toms AD. The epidemiology of revision total knee and hip arthroplasty in England and Wales: a comparative analysis with projections for the United States. A study using the National Joint Registry dataset. Bone Joint J. 2015;97(8):1076-81.

4. Younger TI, Bradford MS, Magnus RE, Paprosky WG. Extended proximal femoral osteotomy: a new technique for femoral revision arthroplasty. J Arthroplasty. 1995;10(3):329-38.

5. Chen WM, McAuley JP, Engh CA Jr, Hopper RH Jr, Engh CA. Extended slide trochanteric osteotomy for revision total hip arthroplasty. J Bone Joint Surg Am. 2000;82(9):1215-9.
6. Mardones R, Gonzalez C, Cabanela ME, Trousdale RT, Berry DJ. Extended femoral osteotomy for revision of hip arthroplasty: results and complications. J Arthroplasty. 2005;20(1):79-83.

7. Huffman GR, Ries MD. Combined vertical and horizontal cable fixation of an extended trochanteric osteotomy site. J Bone Joint Surg Am. 2003;85(2):273-7.

8. Charity J, Tsiridis E, Gusmao D, Bauze A, Timperley J, Gie G. Extended trochanteric osteotomy followed by cemented impaction allografting in revision hip arthroplasty. J Arthroplasty. 2013;28(1):154-60.

9. MacDonald SJ, Cole C, Guerin J, Rorabeck CH, Bourne RB, McCalden RW. Extended trochanteric osteotomy via the direct lateral approach in revision hip arthroplasty. Clin Orthop Relat Res. 2003;(417):210-6.

10. Kim YM, Lim ST, Yoo JJ, Kim HJ. Removal of a well-fixed cementless femoral stem using a microsagittal saw. J Arthroplasty. 2003;18(4):511-2.

11. Arif M, Sivananthan S, Choon DS. Revision of total hip ar- 
Park et al. Anterior Cortical Window in Revision Hip Arthroplasty

Clinics in Orthopedic Surgery • Vol. 11, No. 4, $2019 \bullet$ www.ecios.org

throplasty using an anterior cortical window, extensive strut allografts, and an impaction graft: follow-up study. J Orthop Surg (Hong Kong). 2004;12(1):25-30.

12. Jack CM, Molloy DO, Esposito C, Walter WL, Zicat B, Walter WK. Limited slot femorotomy for removal of proximally coated cementless stems: a 10-year follow-up of an unreported surgical technique. J Arthroplasty. 2013;28(6):10004.

13. Klein AH, Rubash HE. Femoral windows in revision total hip arthroplasty. Clin Orthop Relat Res. 1993;(291):164-70.

14. Moreland JR, Marder R, Anspach WE Jr. The window technique for the removal of broken femoral stems in total hip replacement. Clin Orthop Relat Res. 1986;(212):245-9.

15. Yoo JI, Lee TH, Kim JY, Kim JH, Ha YC. Outcomes of hip arthroscopy in a military population are similar to those in the civilian population: matched paired analysis at 2 years. Arthroscopy. 2018;34(7):2096-101.

16. Compston A. Aids to the investigation of peripheral nerve injuries. Medical Research Council: Nerve Injuries Research Committee. His Majesty's Stationery Office: 1942; pp. 48 (iii) and 74 figures and 7 diagrams; with aids to the examination of the peripheral nervous system. By Michael O'Brien for the Guarantors of Brain. Saunders Elsevier: 2010; pp. [8] 64 and 94 Figures. Brain. 2010;133(10):2838-44.

17. Meijerink HJ, Gardeniers JW, Buma P, Lemmens JA, Schreurs BW. Hydroxyapatite does not improve the outcome of a bipolar hemiarthroplasty. Clin Orthop Relat Res. 2004; (421):143-50.

18. Callaghan JJ, Dysart SH, Savory CG. The uncemented porous-coated anatomic total hip prosthesis: two-year results of a prospective consecutive series. J Bone Joint Surg Am. 1988; 70(3):337-46.

19. Capello WN, D'Antonio JA, Geesink RG, Feinberg JR, Naughton M. Late remodeling around a proximally HAcoated tapered titanium femoral component. Clin Orthop Relat Res. 2009;467(1):155-65.

20. Gruen TA, McNeice GM, Amstutz HC. "Modes of failure" of cemented stem-type femoral components: a radiographic analysis of loosening. Clin Orthop Relat Res. 1979;(141):1727.

21. Miner TM, Momberger NG, Chong D, Paprosky WL. The extended trochanteric osteotomy in revision hip arthroplasty: a critical review of 166 cases at mean 3-year, 9-month follow-up. J Arthroplasty. 2001;16(8 Suppl 1):188-94.

22. Kang BJ, Ha YC, Ham DW, Hwang SC, Lee YK, Koo $\mathrm{KH}$. Third-generation alumina-on-alumina total hip arthroplasty: 14 to 16-year follow-up study. J Arthroplasty. 2015;30(3):411-5.

23. Frankel A, Booth RE Jr, Balderston RA, Cohn J, Rothman RH. Complications of trochanteric osteotomy: long-term implications. Clin Orthop Relat Res. 1993;(288):209-13.

24. Wieser K, Zingg P, Dora C. Trochanteric osteotomy in primary and revision total hip arthroplasty: risk factors for non-union. Arch Orthop Trauma Surg. 2012;132(5):711-7.

25. Sambandam SN, Duraisamy G, Chandrasekharan J, Mounasamy V. Extended trochanteric osteotomy: current concepts review. Eur J Orthop Surg Traumatol. 2016;26(3):231-45.

26. Schwab JH, Camacho J, Kaufman K, Chen Q, Berry DJ, Trousdale RT. Optimal fixation for the extended trochanteric osteotomy: a pilot study comparing 3 cables vs 2 cables. J Arthroplasty. 2008;23(4):534-8.

27. Zhu Z, Ding H, Shao H, Zhou Y, Wang G. An in-vitro biomechanical study of different fixation techniques for the extended trochanteric osteotomy in revision THA. J Orthop Surg Res. 2013;8:7.

28. Silverton CD, Jacobs JJ, Rosenberg AG, Kull L, Conley A, Galante JO. Complications of a cable grip system. J Arthroplasty. 1996;11(4):400-4.

29. Konan S, Garbuz DS, Masri BA, Duncan CP. Modular tapered titanium stems in revision arthroplasty of the hip: the risk and causes of stem fracture. Bone Joint J. 2016;98(1 Suppl A):50-3.

30. Meek RM, Garbuz DS, Masri BA, Greidanus NV, Duncan CP. Intraoperative fracture of the femur in revision total hip arthroplasty with a diaphyseal fitting stem. J Bone Joint Surg Am. 2004;86(3):480-5. 